\title{
Digestion time and feeding of the pelagic chaetognath Zonosagitta nagae in the laboratory
}

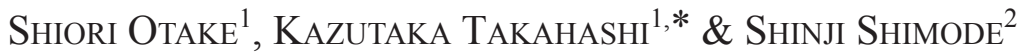 \\ ${ }^{1}$ Department of Aquatic Bioscience, Graduate School of Agricultural and Life Sciences, The University of Tokyo, Tokyo 113- \\ 8657, Japan \\ ${ }^{2}$ Manazuru Marine Center for Environmental Research and Education, Graduate School of Environment and Information \\ Sciences, Yokohama National University, 61, Iwa, Manazuru, Kanagawa 259-0202, Japan
}

Received 7 August 2018; Accepted 29 November 2018 Responsible Editor: Hiroomi Miyamoto

doi: $10.3800 /$ pbr.14.39

\begin{abstract}
Digestion time and feeding of the pelagic chaetognath Zonosagitta nagae, which occurs predominantly in warm waters around Japan, were investigated in the laboratory. Young individuals of Z. nagae ranging from 4.1-7.6 $\mathrm{mm}$ in body length were used for the experiments with adult females of the copepod Acartia steueri as prey. The mean digestion time of $Z$. nagae was $115 \pm 3$ minutes at $20^{\circ} \mathrm{C}$. Temporal change in individual's feeding intensity was observed every $1.5 \mathrm{~h}$ for $24 \mathrm{~h}$ to determine the diel feeding pattern, feeding interval, feeding rates and daily ration. Almost all individuals showed no clear diel rhythm within $24-\mathrm{h}$ at $20^{\circ} \mathrm{C}$ under $12 \mathrm{~L}: 12 \mathrm{D}$ cycle; time interval between feeding was $4.5-6 \mathrm{~h}$ (mode) for individuals that ingested multiple copepods. The number of copepods ingested by a chaetognath ranged from 0 to 5 and on average 2.6 copepods were consumed a day per individual. Specific daily ration in most individuals corresponded to ca. $50 \%$ of its dry weight while some individuals showed the extremes of non-feeding or voracious feeding $\left(>200 \% \mathrm{~d}^{-1}\right)$, indicating that some of the young Z. nagae had an intermittent feeding mode, which would be adaptive to save energy expenditure at low prey densities and to reduce mortality by lowering the risk of predation.
\end{abstract}

Key words: Chaetognatha, digestion, feeding rate, feeing interval, daily ration

\section{Introduction}

Zonosagitta nagae (Alvariño, 1967) is a dominant chaetognath species in the zooplankton community in warm waters around Japanese coastal areas (Marumo and Nagasawa 1973, Itoh et al. 2006, Miyamoto et al. 2012, Ohnishi et al. 2014). This species is particularly abundant in surface waters from spring to summer and predominantly preys on copepods and a variety of other organisms including fish larvae in the field (Nagasawa and Marumo 1972, 1976, Terazaki 2005). This indicates that $Z$. nagae can play an important role in the succession of planktonic communities. Nevertheless, its role in the food web has not been investigated in detail; particularly, accurate estimation on its daily ration (amount of food consumed per day) is lacking, which is crucial for understanding its ecological role

*Corresponding author: Kazutaka Takahashi; E-mail, akazutak@mail. ecc.u-tokyo.ac.jp in planktonic food webs.

The feeding ecology of pelagic chaethognaths, including Zonosagitta nagae, have mainly been studied based on gut content analysis of field samples (Nagasawa and Marumo 1972, Feigenbaum 1991). To obtain daily ration from gut contents, one requires digestion time and diel feeding pattern data (Feigenbaum and Maris 1984), both of which are poorly known in $Z$. nagae. The only available information on digestion time for this species is reported as unpublished data by Terazaki (cited in Nagasawa and Marumo 1972), and it ranged widely from 120 to $300 \mathrm{~min}$ for copepod prey. The utility of this information is also limited by the lack of a description concerning the experimental conditions such as temperature and prey size. Diel changes in feeding intensity of $Z$. nagae is also uncertain. Active feeding by this species at night in the upper water column of Suruga Bay was reported by Nagasawa and Marumo (1972, 1976), while the feeding intensity became higher during the daytime in the population in the near bottom 
layer at the same sampling site (Nagasawa and Marumo 1976). These observations imply that feeding intensity in $Z$. nagae is controlled by ambient prey density, though the details have not yet been clarified. In this study, we determined the digestion time and temporal changes in feeding pattern of $Z$. nagae as well as its maximum daily ration in the laboratory. The results will improve our understanding of the ecological role of $Z$. nagae.

\section{Materials and Methods}

Specimens used in the experiments were collected on 14 July 2016 at a station in the north-western part of Sagami Bay $\left(35^{\circ} 09.9^{\prime} \mathrm{N} 139^{\circ} 10.5^{\prime} \mathrm{E}\right)$ on board the R/V Tachibana of the Manazuru Marine Centre for Environmental Research and Education (MMCER), Yokohama National University. Chaetognaths were collected by towing a plankton net ( $80 \mathrm{~cm}$ mouth diameter, $0.3 \mathrm{~mm}$ mesh) slowly $\left(<0.2 \mathrm{~m} \mathrm{~s}^{-1}\right)$ and obliquely from $50 \mathrm{~m}$ to the surface. Collected animals were kept in an insulating container filled with ambient surface seawater until use in the laboratory. Intact and healthy $Z$. nagae were selected and multiple individuals were placed into a PC bottle (diameter: $6 \mathrm{~cm}$, height: $10 \mathrm{~cm}$ ) containing $250 \mathrm{~mL}$ of $0.2 \mu \mathrm{m}$-filtered seawater (FSW) taken from the field. They were incubated at $20^{\circ} \mathrm{C}$ under 12L:12D conditions with prey (freshly caught adult females of Acartia steueri Smirnov, 1963 from Manazuru port) at a density of $>100$ ind $L^{-1}$. After three days, surviving chaetognaths were selected and placed individually into a smaller PC bottle (diameter: $6 \mathrm{~cm}$, height: $5 \mathrm{~cm}$ ) filled with $125 \mathrm{~mL}$ FSW. Chaetognaths were transferred daily into a fresh medium with new food at a density of 20 copepods per $125 \mathrm{~mL}$ and maintained for 17 days in order to acclimate the chaetognaths to the experimental environment $\left(20^{\circ} \mathrm{C}, 12 \mathrm{~L}: 12 \mathrm{D}\right)$. The density of prey copepods was 80 times higher than annual maximum of mesozooplankton abundance $\left(2000\right.$ inds $\left.\mathrm{m}^{-3}\right)$ in the surface waters (0-100 m) of the sampling site (Shimode et al. 2006).

Digestion time was measured during routine maintenance: whenever we observed the capture of prey by a chaetognath, that individual was immediately isolated into another $125 \mathrm{~mL}$ PC bottle filled with FSW without prey and its gut contents were visually checked every 5-10 minutes until evacuation. After evacuation, the body length of the chaetognath was measured under a dissecting microscope with a digital camera (Leica MZ16+DFC290). All observations were made under dim light at $20^{\circ} \mathrm{C}$. Supplemental data obtained in October with different prey (Oithona oculata Farran, 1913) were also included in the analysis.

To ensure the healthy condition of the experimental animals, diel feeding rhythm and daily ration were measured with a total of 12 individuals of Zonosagitta nagae that survived 17 days of the pre-incubation, and the body length of which ranged from 4.1 to $7.6 \mathrm{~mm}$. As these experiments were intended to measure the maximum dai- ly ration, all individuals were starved for $24 \mathrm{~h}$ before the experiment; then 20 individuals of the copepod Acartia steueri were offered to each chaetognath at $8: 30 \mathrm{~h}$ and the chaetognaths were visually checked for the presence/ absence of gut contents every 1.5 hours to examine their feeding pattern, feeding interval and food consumption rhythm. Multiple prey items in the gut were distinguishable by eye, and the number of fecal pellets was also counted at the end of the incubation to confirm food-consumption. Diel feeding pattern of the population was expressed as mean food-containing ratio (ratio of chaetognaths with food in the gut) and mean feeding rate (number of copepods eaten by a chaetognath per hour). The experiment was carried out over a 24 hours period under the abovementioned constant conditions, except for the brief moment when the chaetognaths were checked for gut contents under dim light. It appears that the experimental conditions were appropriate as all individuals used in the experiments survived for 3 to 25 days after the $24 \mathrm{~h}$ long observation.

Length-dry weight relationships were determined using live Zonosagitta nagae collected in June 2017, also using the same method. Body length of undamaged individuals were measured to the nearest $0.1 \mathrm{~mm}$ under a dissecting microscope (MZ16, Leica) with an eyepiece micrometer. The chaetognaths were then briefly washed with distilled water and placed on pre-weighed tin foil, dried for $24 \mathrm{~h}$ at $50^{\circ} \mathrm{C}$ and weighed to the nearest $0.1 \mu \mathrm{g}$ with a microbalance (MSE6.6S, Sartorius). Dry weight of prey copepods was also measured: twenty to twenty-five freshly caught individuals were placed on precombusted glass fiber filters (Whatman GF/F) and rinsed, dried, and weighed in the same manner as above in order to determine the individual dry weight of prey.

\section{Results}

Digestion times measured for four individuals, plus supplemental data gathered in October, showed little variation at $20^{\circ} \mathrm{C}$, with a mean of $115 \pm 2.9$ minutes (Table 1). Differences in values between the two prey species were not obvious.

The length-dry weight relationship was established based on 27 samples (Fig. 1) and is described by the following equation:

$$
\mathrm{BW}=0.219 \mathrm{BL}^{2.933} \quad(\mathrm{n}=27, \mathrm{r}=0.928)
$$

where $\mathrm{BW}$ is body dry weight in $\mu \mathrm{g}$ and $\mathrm{BL}$ is body length in $\mathrm{mm}$. Dry weights of the adult female Acartia steueri and Oithona oculata prey were $6.60 \pm 0.71 \mu \mathrm{g}$ ind $^{-1}(\mathrm{n}=4)$ and $2.45 \pm 0.31 \mu \mathrm{g} \mathrm{ind}^{-1}(\mathrm{n}=3)$, respectively.

The number of copepods ingested daily by each chaetognath ranged from 0 to 5 (on average 2.6). Almost all individuals showed no clear diel feeding rhythm (Fig. 2). Among the fed chaethognaths that fed, most individuals (85\%) had a single copepod in their gut, but some individu- 
Table 1. Digestion time of Zonosagitta nagae observed in the laboratory at $20^{\circ} \mathrm{C}$. All chaetognaths and copepods were collected from Sagami Bay.

\begin{tabular}{ccccc}
\hline Date & Observation time & Body length of Z. nagae $(\mathrm{mm})$ & Prey & Digestion time (min) \\
\hline 20 July 2016 & $14: 05-15: 55$ & 5.6 & Acartia & 110 \\
20 July 2016 & $16: 45-18: 45$ & 4.4 & Acartia & 120 \\
21 July 2016 & $21: 30-23: 00$ & 5.4 & Acartia & 120 \\
4 Oct 2017 & $16: 00-17: 50$ & 5.6 & Oithona & 110 \\
\hline Mean \pm S.E. & & $5.3 \pm 0.3$ & & $115 \pm 2.9$ \\
\hline
\end{tabular}

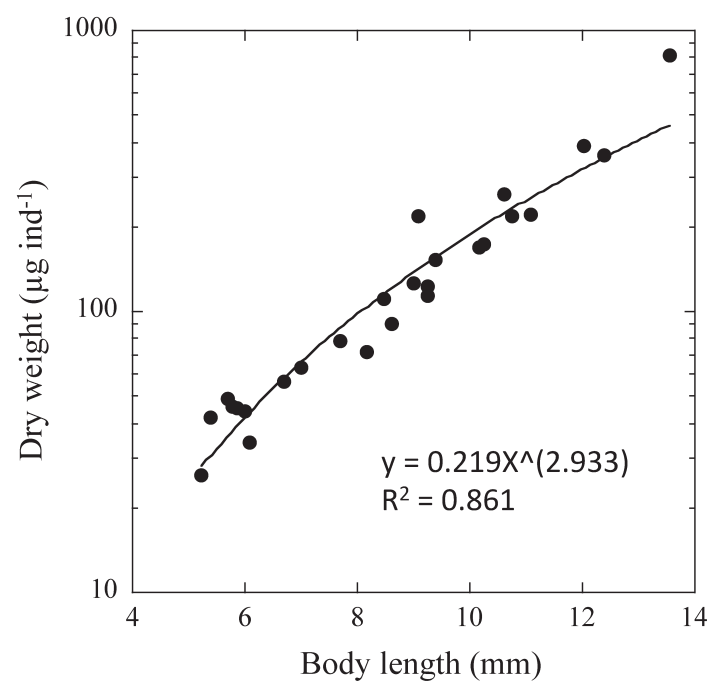

Fig. 1. Allometric relationship between body length and dry weight of Zonosagitta nagae collected in Sagami Bay in June 2017. $\mathrm{Y}$ axis is expressed with log scale.

als $(15 \%)$ had $2-3$ copepods in their gut. Feeding interval (i.e., time interval between feeding) was variable; the mode was within $4.5-6 \mathrm{~h}$ and the mean was $4.3 \pm 3.2 \mathrm{~h}$. Some individuals showed intensive feeding period with intervals shorter than $1.5 \mathrm{~h}$ (Fig. 3), while some did not feed at all within the $24 \mathrm{~h}$ period (Fig. 2).

The observed mean food-containing ratio was $14 \%$ and the differencein this value between light $(15 \%)$ and dark (13\%) conditions was not obvious (Fig. 4a). Mean feeding rate on Acartia steueri throughout the experiments was $0.11 \pm 0.30$ inds per chaetognath per hour and there was no statistical difference between light $(0.13)$ and dark (0.09) periods (t-test, $p=0.42$, Fig. $4 \mathrm{~b}$ ). Although no significant difference was found between the first and the second half $(10: 00-20: 30$ vs. $22: 00-8: 30)$ of the observation period (t-test, $p=0.06$ ), a significant decreasing trend in feeding rate with incubation time was observed $(\mathrm{n}=16, \mathrm{r}=0.52$, $p<0.05$ ).

Daily ration for chaetognaths used in the experiments was calculated with the allometric relationship (Fig. 1) and dry weight of the prey. Generally, the daily ration seemed to correlate with chaetognath body size, while some individuals also showed high variability in feeding activity, ranging from intensive feeding to no feeding (Fig. 5a).

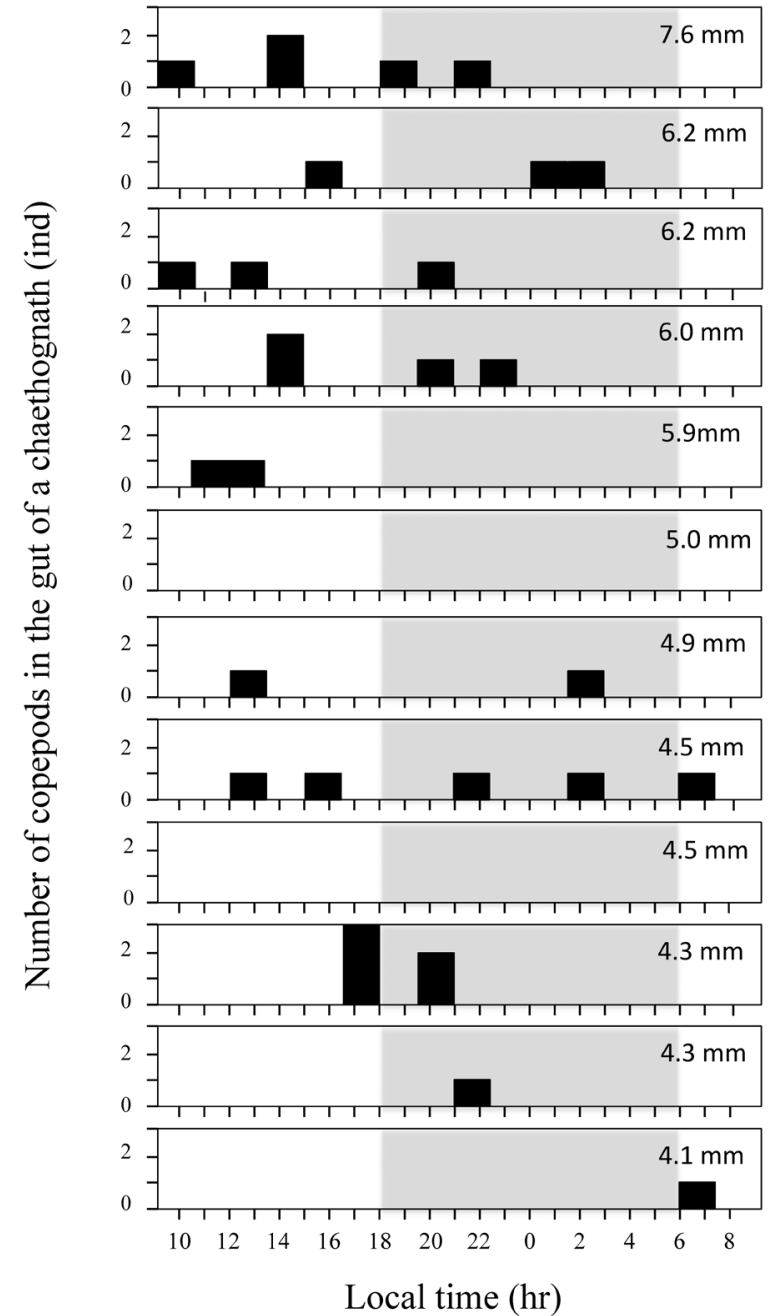

Fig. 2. Temporal change in individual feeding activity in Zonosagitta nagae on the copepod Acartia steueri in the laboratory during a 24-hour observation period in the laboratory. Body length of experimental animal is shown in each panel. Grey shading indicates the dark period.

Overall, the specific daily rations for most individuals were about $50 \%$ of their body dry weight, though it varied from 0 to $200 \%$ of their body weight, particularly in smaller individuals where the body length was $4.3-5.0 \mathrm{~mm}$ (Fig. 5b). 


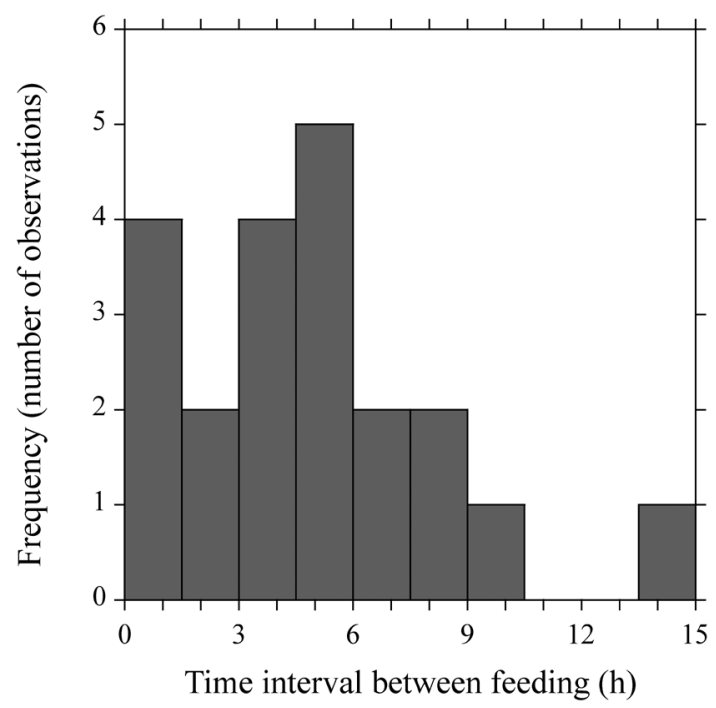

Fig. 3. Frequency distribution in feeding interval in Zonosagitta nagae that fed on multiple prey items during a 24-h observation period in the laboratory.

\section{Discussion}

The mean digestion time for Zonosagitta nagae was $115 \pm 3$ minutes for small copepod prey at $20^{\circ} \mathrm{C}$ in our experiments. This value was within the range of the reported digestion time in other chaetognaths at the same temperature range (Table 2). Digestion time in $Z$. nagae has been reported at 120-300 minutes for copepod prey (Terazaki, unpublished data cited in Nagasawa and Marumo 1972). However, it is difficult to compare the two studies as Terazaki's data lack information about water temperature, size of prey and size of chaetognaths, all of which are known to affect the digestion time (Feigenbaum and Maris 1984). This study is, therefore, the first report of digestion time in $Z$. nagae with detailed information such as water temperature $\left(20^{\circ} \mathrm{C}\right)$, body length of chaetognaths $(4.4-5.6 \mathrm{~mm})$ and prey species (Acartia steueri and Oithona oculata). Our results can be used as a benchmark when estimating food intake by $Z$. nagae in the field, since the small copepods used in this study are among the main prey of $Z$. nagae smaller than $10 \mathrm{~mm}$ (Nagasawa and Marumo 1976). As $Z$. nagae larger than $10 \mathrm{~mm}$ also ingest larger copepods such as Calanus spp., Candacia spp. and Pareuchaeta spp. in the field (Nagasawa and Marumo 1976), further studies concerning digestion time with larger prey are required.

Zonosagitta nagae did not show evidence of a diel feeding rhythm in our experiments and preyed on copepods regardless of light condition, even though it is generally known that planktonic chaetognaths, including Z. nagae, feed more actively at night than in daytime in the field (Nagasawa and Marumo 1972, 1976, Feigenbaum and Maris 1984). Several explanations can be offered for this discrepancy. First is the effect of starvation. Although there was no statistical difference in the mean feeding rates in the first half and the second half of the experimen-
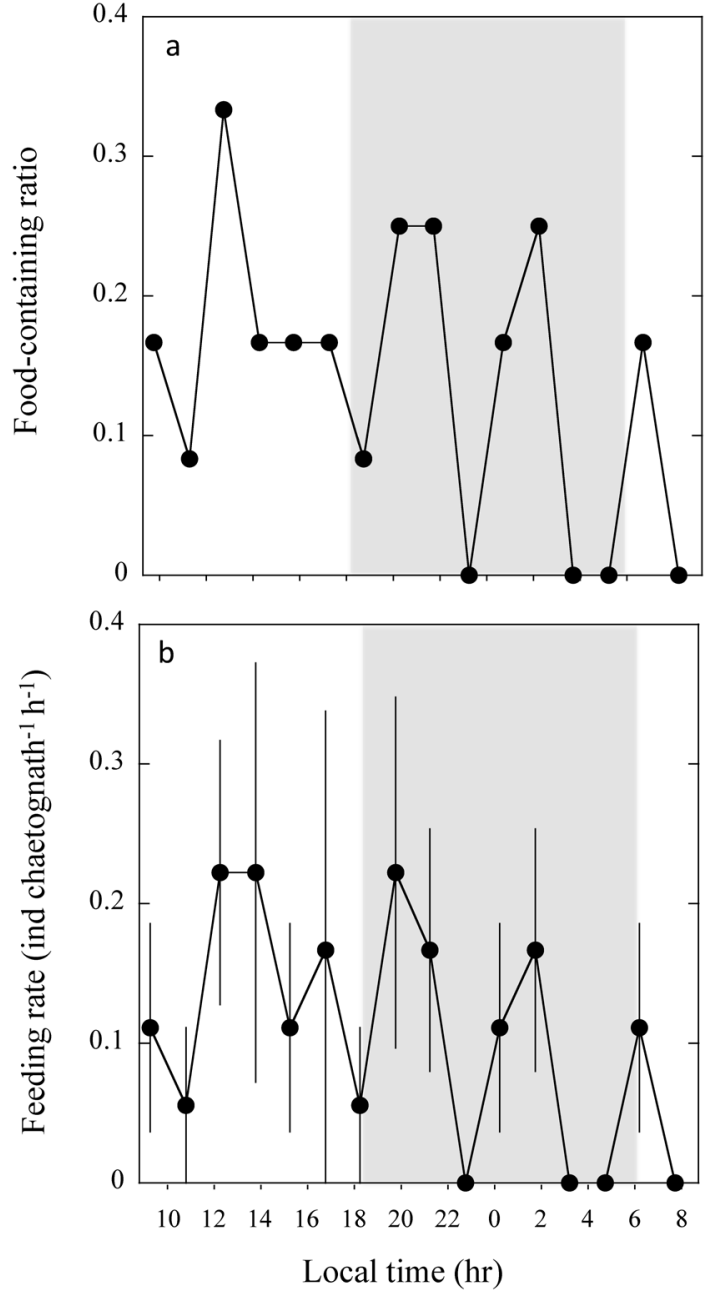

Fig. 4. Diel feeding pattern of Zonosagitta nagae on the copepod Acartia steueri during a 24-h observation period in the laboratory. a) mean food-containing ratio and b) mean feeding rate. Vertical bars indicate \pm 1 S.E. Grey shading indicates the dark period.

tal period, feeding rate gradually decreased with time during the observations. The young specimens $(4.1-7.6 \mathrm{~mm})$ used in this study tend to have small energy reserves and high metabolic requirements; therefore, the 24-h starvation period during the pre-incubation may have affected their feeding patterns as has been reported in other chaetognath species (Kuhlmann 1977). Moreover, constant prey concentrations may affect the diel feeding pattern. Nagasawa and Marumo (1976) reported that $Z$. nagae in a near bottom habitat fed more actively on copepods during the day than at night, while the feeding activity in the population in the upper water column was higher at night (Nagasawa and Marumo 1972, 1976). This may be attributed to a daytime increase in prey density in the near bottom habitat due to diurnal descent in the vertically migratory prey. Based on these observations, Nagasawa and Marumo (1976) concluded that the daily cycle in feeding activity in $Z$. nagae varied depending on prey density rather than on the ambient light conditions. The results of this study agree 
with their conclusion and indicate that the presence of ambient light was not a critical factor inhibiting the feeding behaviour of $Z$. nagae in its young stages.

Since we observed individual feeding events at intervals shorter than the digestion time, the results allowed analysis
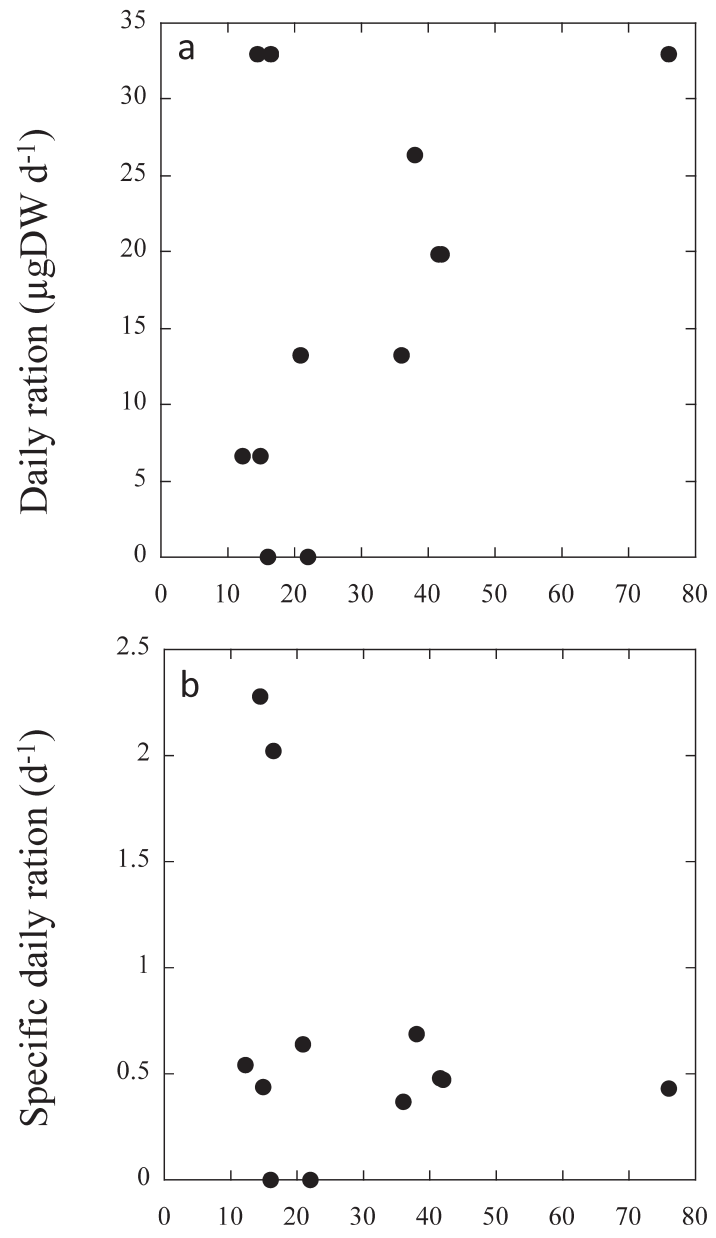

\section{Body weight ( $\mu \mathrm{gDW})$}

Fig. 5. Relationship between body weight and a) daily ration and b) specific daily ration in Zonosagitta nagae with the copepod Acartia steueri as prey, calculated based on the data from a 24-hour incubation in the laboratory. of the feeding interval which has never been reported in pelagic chaetoganths. The mode of the feeding interval in chaetognaths that had ingested multiple copepods during the experiment was found to be $4.5-6 \mathrm{~h}$, although another peak was found at $0-1.5 \mathrm{~h}$, implying that foraging behaviour in Zonosagitta nagae may be enhanced as a hunger response after several hours of digestion and assimilation of ingested prey.

Daily ration of Zonosagitta nagae generally increased with body size, except for some individuals that showed the extremes of non-feeding or voracious feeding. Overall, the specific daily ration of $Z$. nagae corresponded to ca. $50 \%$ of its dry weight and the voracious feeding individuals ingested $>200 \%$ of their dry weight, while two out of 12 individuals did not feed at all in $24 \mathrm{~h}$. In the field population, the mean specific daily ration of Z. nagae of $8-23 \mathrm{~mm}$ in body length was estimated at $37.6 \%$ of its dry weight by Nagasawa and Marumo (1972), while Feigenbaum and Maris (1984) claimed a possibility of overestimation and revised it to $18.8 \%$. In either case, the daily ration shown in this study is clearly higher than the estimates for field populations. This may be caused by the high prey concentration in the experimental bottle in addition to the presence of a $24 \mathrm{~h}$ starvation period prior to the experiments, indicating that the daily ration shown in this study is a maximum for this species in this size range. Furthermore, the small animal size in our experiments (4.1$7.6 \mathrm{~mm}$ ) is likely another cause, since young chaetognaths generally have higher specific daily rations than larger individuals (Feigenbaum 1979, Reeve 1980). Extremely high specific feeding rates $(>200 \%)$ found in some individuals also indicate elevated feeding activities of young individuals. At the same time the presence of non-feeding individuals, even after $24 \mathrm{~h}$ starvation, indicates that small sized individuals of this species are able to survive in low food environments at least for a few days. The pattern found in the specific feeding rates of $Z$. nagae implies that this species has two feeding modes; continuous and intermittent feeding. A continuously feeding individual consumes $50 \%$ of its body dry weight a day, while an intermittently feeding individual might feed intensively in-between extended non-feeding periods. Although we were not able to determine the cause for the intermittent feeding, this feeding

Table 2. Comparison of digestion time of chaethognaths with copepod prey at $20-25^{\circ} \mathrm{C}$ (Modified from the Table in Feigenbaum 1991 ).

\begin{tabular}{cclcc}
\hline \multicolumn{1}{c}{ Species } & Temperature $\left({ }^{\circ} \mathrm{C}\right)$ & \multicolumn{1}{c}{ Prey } & Digestion time (min) & References \\
\hline Aidanosagitta crassa & $22-24$ & Acartia clausi & 102 & Nagasawa (1985) \\
& $22-24$ & Tigriops japonicus & 168 & Canico and Grant (1985) \\
Ferosagitta hispida & 25 & Copepods & 137 & Spyzer (1978) \\
Flacciagitta enflata & 21 & Copepods (2inds) & 190 & Canico and Grant (1985) \\
Parasagitta tenuis & 23 & Copepods & 116 & This study \\
Zonosagitta nagae & 21,25 & Acartia tonsa & 110 & Acartia steueri \\
& 20 & Oithona oculata & &
\end{tabular}


mode is potentially adaptive to save energy expenditure when prey density in the environment is low. An intermittent feeding mode would also help lower the mortality of young chaetognaths as less active foraging behaviour decreases the encounter rate with potential predators, including other chaetognaths. Cannibalism is known to occur commonly in chaetognaths, including Z. nagae (Nagasawa and Marumo 1972, Pearre 1982).

Chaetognaths are ubiquitous in the marine environment and are among the most abundant carnivorous plankton, often exceeding $20-30 \%$ of the copepod biomass (Reeve 1970); hence they are important secondary consumers in planktonic food webs. Nevertheless, information on their physiological parameters, which is vital for ecosystem models, is limited partly because of the difficulty in obtaining the data using chaetognaths in captivity. This study shows that Zonosagitta nagae can be maintained in the laboratory for more than two weeks and thus further study about its feeding and growth characteristics in the laboratory will improve our understanding of pelagic chaetognaths.

\section{Acknowledgements}

We are grateful to the staff of the MMCER for their assistance with the sampling. We also thank H. Miyamoto and T. Ohnishi for their helpful information about the biology of chaetognaths. This study was supported by a Grantin-Aid for Scientific Research (B) from the Ministry of Education, Science, Sports and Culture to K.T. (24310007) and a grant from the Research Institute of Marine Invertebrates Foundation to K.T.

\section{References}

Canico MF, Grant GC (1985) The feeding and diet of Sagitta tenuis (Chaetognatha) in the lower Chesapeake Bay. J Plankton Res 7: 175-188.

Feigenbaum D (1979) Daily ration and specific daily ration of the chaetognath Sagitta enflata. Mar Biol 54: 75-82.

Feigenbaum D (1991) Food and feeding behaviour. In: Biology of Chaetognaths (eds Bone Q, Kapp H, Pierrot-Bults AC). Oxford University Press, Oxford, pp. 45-54.
Feigenbaum DL, Maris RC (1984) Feeding in the Chaetognatha. Oceanogr Mar Biol Ann Rev 22: 343-392.

Itoh H, Ono Y, Kubota T (2006) Vertical distribution of largesize chaetognaths in Suruga Bay, Central Japan. J School Mar Sci Tech Tokai Univ 4: 1-13.

Kuhlmann D (1977) Laboratory studies on the feeding behaviour of the chatognaths Sagitta setosa J. Müller and S. elegans Verril with special reference to fish eggs and larvae as food organisms. Meeresforsch 25: 163-171.

Marumo R, Nagasawa S (1973) Pelagic chaetognaths in Sagami Bay and Suruga Bay, central Japan. J Oceanogr Soc Jpn 29: 267-275.

Miyamoto H, Nishida S, Kurida K, Tanaka Y (2012) Vertical distribution and seasonal variation of pelagic chaetognaths in Sagami Bay, central Japan. Plankton Benthos Res 7: 41-54.

Nagasawa S (1985) The digestive efficiency of the chaetognath Sagitta crassa Tokioka, with observation on the feeding process. J Exp Mar Biol Ecol 87: 271-282.

Nagasawa S, Marumo R (1972) Feeding of a pelagic chaetognath, Sagitta nagae Alvariño in Suruga Bay. J Oceanogr Soc Jpn 28: 181-186.

Nagasawa S, Marumo R (1976) Further studies in the feeding habits of Sagitta nagae Alvariño in Suruga Bay, Central Japan. J Oceanogr Soc Jpn 32: 209-218.

Ohnishi T, Ueda H, Kuroda K (2014) Community structure and spatial distribution of chaetognaths in Tosa Bay on the temperate Kuroshio coast of Japan. Plankton Benthos Res 9: 176-187.

Pearre S Jr (1982) Feeding by Chaetognatha: Aspects of interand intra-specific predation. Mar Ecol Prog Ser 7: 33-45.

Reeve MR (1970) The biology of Chaetognatha I. Quantitative aspects of growth and egg production in Sagitta hispida. In Marine Food Chains (ed Steele JH). Oliver and Boyd Edinburgh pp. 168-189.

Reeve MR (1980) Comparative experimental studies on the feeding of chaetognaths and ctenophores. J Plankton Res 2: 381393.

Shimode S, Toda T, Kikuchi T (2006) Spatio-temporal changes in diversity and community structure of planktonic copepods in Sagami Bay, Japan. Mar Biol 148: 581-597.

Spyzer JP (1978) Feeding rate of the chaetognath Sagitta enflata in nature. Estur Coast Mar Sci 7: 567-575.

Terazaki M (2005) Predation on anchovy larvae by a pelagic Chaetognatha, Sagitta nagae in the Sagami Bay, central Japan. Coast Mar Sci 29: 162-164. 